\title{
A Compact Circular Loop Inspired Frequency and Bandwidth Reconfigurable Antenna for 4G, 5G, and $X$ - Band Applications
}

\author{
Maryam RASOOL ${ }^{1}$, Aabia KHAN ${ }^{1}$, Farooq BHATTI ${ }^{1}$, Bilal IJAZ ${ }^{2}$, Adnan IFTIKHAR ${ }^{2}$ \\ ${ }^{1}$ Dept. of Electrical Engineering, Military College of Signals, National University of Sciences and Technology (NUST), \\ Islamabad, Pakistan \\ ${ }^{2}$ Dept. of Electrical and Computer Engineering, COMSATS University, Islamabad, Pakistan \\ maryamrasool@mcs.edu.pk
}

Submitted November 14, 2019 / Accepted June 11, 2020

\begin{abstract}
This paper presents a printed patch antenna design to achieve frequency and bandwidth reconfigurability. Two RF PIN diodes are simultaneously operated to achieve the multi-reconfigurability operation. The patch is inspired from a circular loop design. The basic structure of a loop is altered, and PIN diodes are integrated into the patch. The antenna operates in dual band configuration at 3.42 and $8.02 \mathrm{GHz}$ in the diodes 'OFF' state, whereas the antenna switches to triple band operation at 2.21, 4.85, and $10.19 \mathrm{GHz}$ in the diodes 'ON' state. Moreover, the antenna also exhibits an increased bandwidth from 7.54 to $12 \mathrm{GHz}$ in the diodes 'ON' state, as compared to a narrow bandwidth from 7.71 to $8.48 \mathrm{GHz}$ in the diodes 'OFF' state. The proposed antenna structure is implemented and fabricated using FR4 epoxy substrate of relative permittivity 4.4, and thickness $1.6 \mathrm{~mm}$. Implemented design exhibits measured gains of $3.06 \mathrm{dBi}, 2.81 \mathrm{dBi}$, and $2.92 \mathrm{dBi}$ at 2.21, 4.85, and $10.19 \mathrm{GHz}$ in the PIN diodes 'ON' state, respectively, while in the PIN diodes 'OFF' state, at $3.42 \mathrm{GHz}$ the gain is $3.03 \mathrm{dBi}$ and at $8.02 \mathrm{GHz}$ the gain is $3.37 \mathrm{dBi}$. Overall, simulation results agree well with the measured results.
\end{abstract}

\section{Keywords}

Circular loop, PIN diodes, reconfigurable antennas, triple band operation

\section{Introduction}

Multiband printed and frequency reconfigurable antennas have gained much attention in last few decades due to congestion of the electromagnetic spectrum. The reconfigurable antennas operating on multiple bands can serve to reduce the complexity of hardware components as they provide multiple functionalities in one compact design. Multiband reconfigurable antennas have appeared as potential candidates for modern fourth and fifth generation
(4G, 5G) wireless communication applications, as they improve performance of a communication system by reducing size, complexity, and cost of the antenna structure. Different techniques have been presented in the literature for achieving multiband reconfigurability. Many of these techniques focus on altering the current flow on the antenna structure and creation of different current paths by using stacked structures, elongated arms, and strips in the antenna design. However, many such techniques result in an increased structural complexity as larger ground plane is involved in the designs [1]. Another technique to achieve multiband reconfigurability operation is LC (inductor-capacitor) resonator loading. The basic principle of LC resonator loading focuses on embedding the printed antenna structure with different sets of LC elements, as a result the antenna structure resonates at different frequencies [2]. Techniques focusing on defected ground structures have also been explored for achieving multiband reconfigurability in printed antennas [3]. In addition, circular loops and ring structures have also been investigated to achieve frequency reconfigurability [4]. Printed antennas can be designed to perform the reconfigurability operation, not only concerning the resonant frequency, but also concerning certain other antenna parameters like bandwidth, polarization, and radiation pattern. Number of reconfigurability operations offered by the antenna generally depends upon number of active elements employed in the design [5], [6]. The reconfigurability operation can be achieved by either mechanical switching (reed switches) or electronic switching (PIN diodes). Radio Frequency (RF) microelectromechanical systems (MEMS) switches and varactor diodes are another possible option to design multiband reconfigurable antennas [7], [8]. RF MEMS switches usually offer a low switching speed of 1 to $200 \mu \mathrm{sec}$ for most applications [7]. PIN diodes on the other hand, provide fast switching speeds of 1 to $100 \mathrm{nsec}$ [9]. Mechanical switches result in complex and bulky structures whereas PIN diodes can easily be integrated on antenna substrates, thereby making them potentially suitable candidates for multiband reconfigurability operations. 


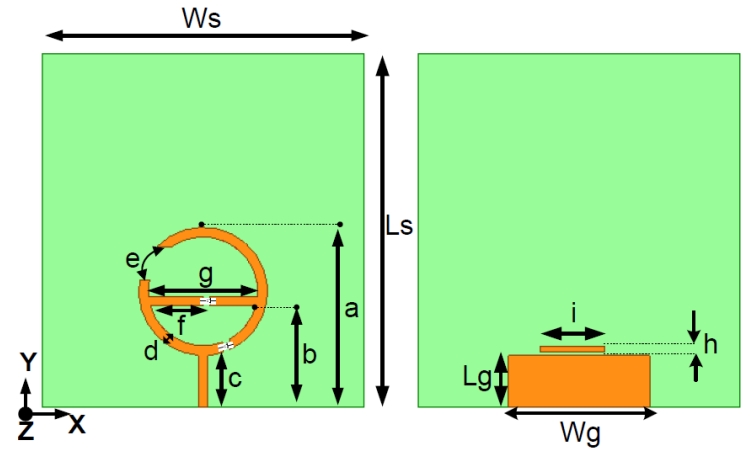

Fig. 1. Detailed layout of the proposed antenna, radiating patch (left) and modified ground (right). Dimensions $(\mathrm{mm})$ are: $\mathrm{Ls}=55, \mathrm{Ws}=50, \mathrm{a}=28, \mathrm{~b}=15.75$, $\mathrm{c}=8.02, \mathrm{~d}=1.5, \mathrm{e}=5.25, \mathrm{f}=8.19, \mathrm{~g}=17, \mathrm{~h}=1$, $\mathrm{i}=10, \mathrm{Lg}=8$ and $\mathrm{Wg}=22$.

Researchers have explored the idea of using PIN diodes to obtain frequency reconfigurability, polarization reconfigurability [10], [11], and radiation pattern reconfigurability [12]. In [13], an antenna exhibiting bandwidth reconfigurability, for WLAN (Wireless Local Area Network) and WiMAX (Worldwide Interoperability for Microwave Access) operations is presented. Researchers have also investigated the use of slots, slit structures, parasitic patches, and modified ground planes with PIN diodes to achieve multi-reconfigurability operation targeting both frequency and bandwidth switching [14], [15].

Wireless communication in recent times has seen tremendous growth from first generation $(1 \mathrm{G})$ to fourth generation $(4 \mathrm{G})$, and today the world is moving towards deployment of fifth generation $(5 \mathrm{G})$ technologies. $2 \mathrm{GHz}$ to $8 \mathrm{GHz}$ frequencies have been used for $4 \mathrm{G}$ communication [16], whereas the frequency bands for $5 \mathrm{G}$ technologies are broadly classified as the low frequency band from $600 \mathrm{MHz}$ to $6 \mathrm{GHz}$ (the sub- $6 \mathrm{GHz}$ band), and the high frequency band from $24 \mathrm{GHz}$ to $71 \mathrm{GHz}$ (the mm wave band) [17]. Mobile communication services, high speed internet, data intensive interactive user services, telemedicine, and high definition video are some popular applications of $4 \mathrm{G}$ and $5 \mathrm{G}$ communication technologies [18]. In addition, frequency range from $8 \mathrm{GHz}$ to $12 \mathrm{GHz}$ (generally known as the X-band) is popularly used in radars and satellite communication systems [19]. Many services of 5G in initial deployment phase will be offered using the already existing Long Term Evolution (LTE) frequency bands [20]. Antenna designs that offer switching between $4 \mathrm{G}$ and $5 \mathrm{G}$ frequencies as per demand is a popular research topic today [21].

This paper explores the switching phenomenon between different frequencies of $4 \mathrm{G}, 5 \mathrm{G}$ and $\mathrm{X}$-band, not only in terms of frequency reconfigurability but also in terms of bandwidth reconfigurability. The proposed design consists of a circular loop inspired structure which has been modified to accommodate two PIN diodes, as shown in Fig. 1. The diodes placement allows them to be turned 'ON' or 'OFF' simultaneously. Triple band operation (at $2.21,4.85$, and $10.19 \mathrm{GHz}$ ) is achieved when both diodes are turned ' $\mathrm{ON}$ ' whereas dual band operation (at 3.54 and $8.02 \mathrm{GHz}$ ) is achieved when both diodes are turned 'OFF'. In addition, bandwidth switching, from narrowband to wideband, is also observed in the diodes 'ON' state. Resonant frequencies of the proposed design target not only the pure $4 \mathrm{G}, 5 \mathrm{G}$, and $\mathrm{X}$-band frequencies, but also the shared frequency bands between existing $4 \mathrm{G}$ and $5 \mathrm{G}$ communication services. The proposed antenna can find applications in devices involved in 4G Advanced Wireless Services (AWS - from 2180 to $2200 \mathrm{MHz}$ [22]), WiMAX services (3400 to $3600 \mathrm{MHz}$ [23]), n48 (3550 to $3700 \mathrm{MHz}$ ), and $\mathrm{n} 78$ (3300 to $3800 \mathrm{MHz}$ ) bands in $5 \mathrm{G}$ new radio (NR) services [24]. The proposed antenna can also be used in modern devices utilizing the licensed bands of $5 \mathrm{G}$ in China (3300 to $3600 \mathrm{MHz}$ and 4800 to $5000 \mathrm{MHz}$ ) and in Europe (3400 to $3800 \mathrm{MHz}$ ) [17], as well as fixed and mobile satellite services in the X-band ( $8 \mathrm{GHz}$ to $12 \mathrm{GHz}$ ) [19].

\section{Antenna Structure Design}

The presented antenna design comprises of a compact structure inspired from a circular loop [25] and includes a modified partial ground plane. The antenna is designed using High Frequency Structure Simulator (HFSS), a full wave 3D electromagnetic software. Circular loop and ringshaped patch structures can be effectively used to design a multiband antenna [26]. Initially, a conventional loop antenna with radius $r$ of $10 \mathrm{~mm}$ and strip width $d$ of $1.5 \mathrm{~mm}$ was designed. The strip width is converted into wire radius using the following expression, given in [27]:

$$
w r=\frac{d}{4}
$$

where $d$ is the strip width of the printed antenna and $w r$ is the wire radius. With known wire and loop radius, another parameter called the thickness factor is computed. Thickness factor classifies any loop antenna as thick or thin. Thin antennas can effectively resonate at multiple frequencies [27]. The thickness factor, denoted by $T F$ is given in [28]:

$$
T F=2 \ln \left(\frac{2 \pi r}{w r}\right)
$$

where $r$ denotes the loop radius. The thickness factor $T F$ for the initially designed circular loop antenna comes out to be 10.24 , making it a thin loop antenna $(T F>9)$ [28]. The design is realized on a $50 \times 55 \mathrm{~mm}^{2}$ FR4 epoxy substrate with a thickness of $1.6 \mathrm{~mm}$. Figure 1 depicts the complete layout and detailed dimensions of final antenna design. As shown in Fig. 1, the design consists of a ring-shaped patch inspired from the conventional circular loop structure. An arc of length $e$ has been removed from the circular loop structure, and a rectangular strip of width $d$ and length $g$ has been added, to obtain the final antenna design. A $50 \Omega$ microstrip line feed structure has also been incorporated to excite the proposed antenna design. 


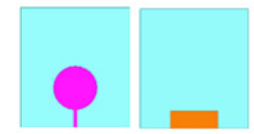

(A)

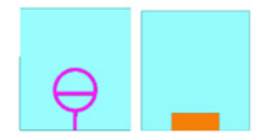

(c)

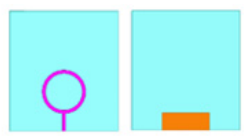

(B)

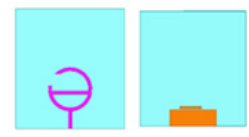

(D)
Fig. 2. Antenna design evolution steps (top and bottom): (A) Design A, (B) Design B, (C) Design C, and (D) Design D.

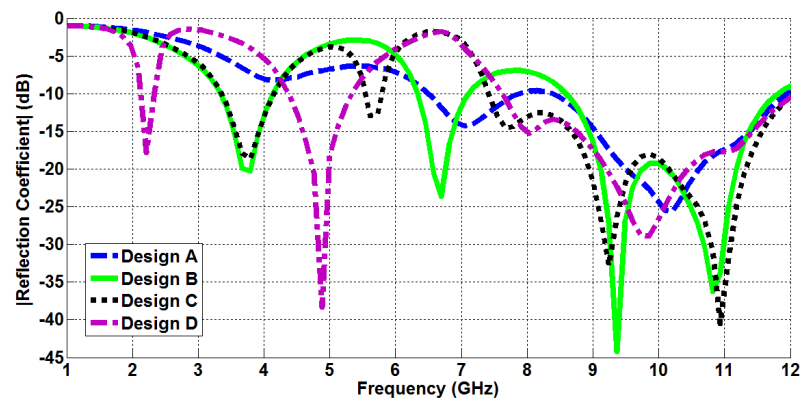

Fig. 3. |Reflection Coefficient $\mid(\mathrm{dB})$ for antenna design evolution steps.

It was observed during the design process that arc removal from circular loop [25] along with addition of middle rectangular strip [29] and partial ground structure [30] not only aid in achieving multi-band operation but these modifications also serve to increase the operational bandwidth of the antenna. A small rectangular strip placed at a distance of $0.5 \mathrm{~mm}$ from the partial ground plane further helped in enhancing the bandwidth and efficiency of the design.

\subsection{Design Evolution}

The major design steps involved in evolution of antenna structure are represented in Fig. 2. For each design in Fig. 2, |Reflection Coefficient| (dB) is plotted in Fig. 3, to observe the impedance matching characteristics. The evolution of the proposed antenna structure started with a simple circular patch and a rectangle shaped partial ground labelled as Design A in Fig. 2. The results in Fig. 3 reveal that Design A was able to cover major portion of the $\mathrm{X}$-band. The structure was then modified into a circular loop design, labelled as Design B in Fig. 2, to achieve multiband operation. Results for Design B, in Fig. 3 confirm that circular loop resulted in a multiband operation. Next step was to modify the operating frequencies and bandwidth of the X-band. A rectangular middle strip of $17 \mathrm{~mm}$ was then added in the center [29]. This modification is labelled as Design C in Fig. 2, whereas the corresponding results are shown in Fig. 3. Results indicate that incorporation of middle rectangular strip enabled the antenna to cover the entire X-band. Finally, an arc of $5.25 \mathrm{~mm}$ was removed from the circular loop [25] and an additional rectangular strip was added on the bottom side [30] to achieve the desired triband operation. This design is labelled as Design D in Fig. 2 and corresponding results are plotted in Fig. 3.

\subsection{Parametric Analysis}

A detailed parametric analysis on various geometrical parameters of the proposed design was performed to better understand the contribution of radiating structures. The removed arc length $e$ was varied from $1.25 \mathrm{~mm}$ to $7.75 \mathrm{~mm}$. The |Reflection Coefficient| (dB) results of each variation are presented in Fig. 4. It can be observed that the resonant frequency of the first band shifts by changing the removed arc length. The desired frequency of $2.21 \mathrm{GHz}$ is achieved when the removed arc length $e$ equals $5.25 \mathrm{~mm}$.

Next parametric analysis was performed on length $g$ of the middle rectangular strip of the patch. The middle rectangular strip was kept connected to the right side of the loop and its length was varied from $5 \mathrm{~mm}$ to $17 \mathrm{~mm}$. Figure 5 presents the |Reflection Coefficient| (dB) results of the analysis. It can be observed that the middle strip length not only controls frequency of the second band, but it also contributes towards increasing the bandwidth of third band (X-band). The variation of the middle strip length particularly helped in selection of PIN diode position 1 for frequency agility. Desired optimum results are obtained when $g$ equals $17 \mathrm{~mm}$ and is completely connected to the circular loop from both sides.

The importance of strip width $d$ as stressed previously, while calculating the thickness factor, can be observed through the parametric analysis represented by Fig. 6. The strip width $d$ was varied from $1.5 \mathrm{~mm}$ to $4.5 \mathrm{~mm}$. It can be observed that a thin antenna is able to resonate at multiple frequencies. The optimized strip width for the implemented design is $1.5 \mathrm{~mm}$. An increase in the strip width vanished the second frequency band, as observed in Fig. 6. The effect of partial ground variation on resonant frequencies was also observed and is depicted in Fig. 7. The variation of strip length $W_{\mathrm{g}}$ from $10 \mathrm{~mm}$ to $22 \mathrm{~mm}$ greatly affected the resonant frequencies. Desired triband results are obtained when $W_{\mathrm{g}}$ is equal to $22 \mathrm{~mm}$. The finalized triband antenna with optimized parameters depicted in Fig. 1 resonates from (2.16-2.27) GHz, (4.3 to 5.3) $\mathrm{GHz}$, and (7.54-12) GHz. The overall dimensions of the final triband antenna were $22 \times 30 \mathrm{~mm}^{2}$. However, the substrate size was increased later to accommodate DC biasing circuit for PIN diode operations.

\subsection{PIN Diodes Integration}

After design optimization and achievement of triband operation, next step was to identify PIN diodes positions and integrate them into the antenna structure. The PIN diodes positions were decided by carefully analyzing the antenna structure, parametric analysis, and surface current distributions of the triband antenna. Figure 8 depicts main radiating patch of the antenna design with clearly marked 
diode positions. The basic idea in identifying these diode positions was to provide different paths to RF currents from feed line to radiating patch, thereby changing the electrical length of the design. PIN diode at position 1 primarily controls the switching of $2.21 \mathrm{GHz}$ frequency band whereas PIN diode at position 2 controls the bandwidth of the X-band. Switching between $3.42 \mathrm{GHz}$ and $4.85 \mathrm{GHz}$ frequencies is controlled when both diodes are

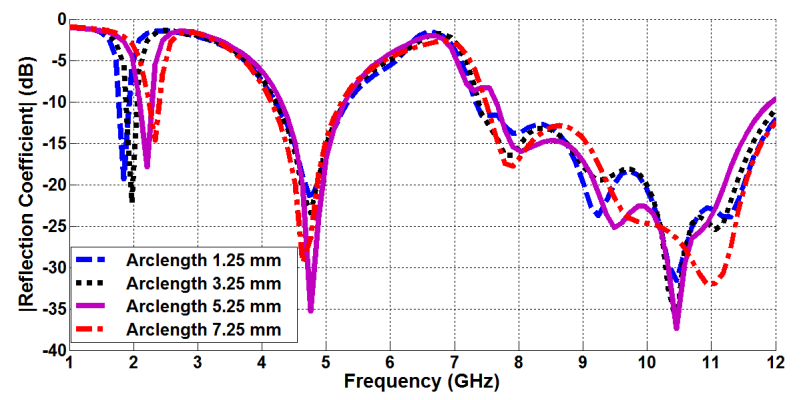

Fig. 4. Effect of arc length $e$ variation on |Reflection Coefficient $\mid(\mathrm{dB})$.

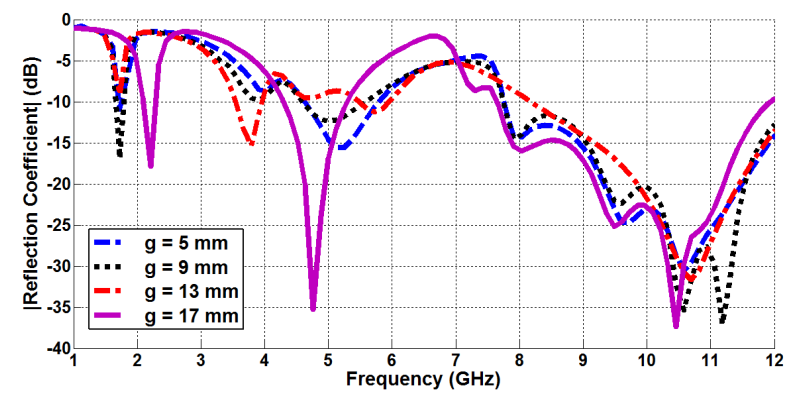

Fig. 5. Effect of middle strip length $g$ variation on $\mid$ Reflection Coefficient| (dB).

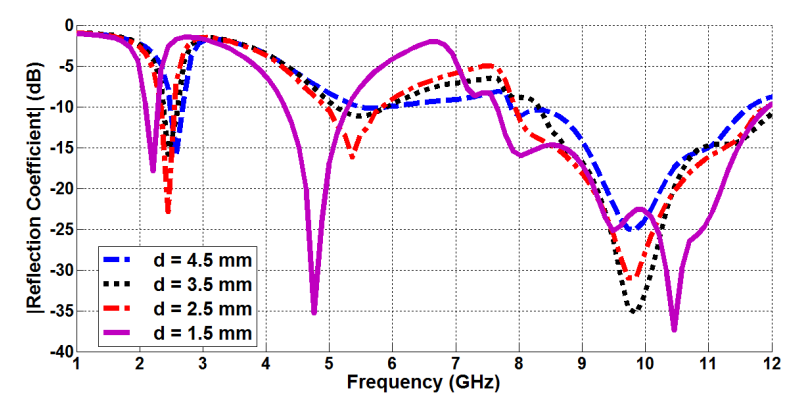

Fig. 6. Effect of strip width $d$ variation on |Reflection Coefficient| (dB).

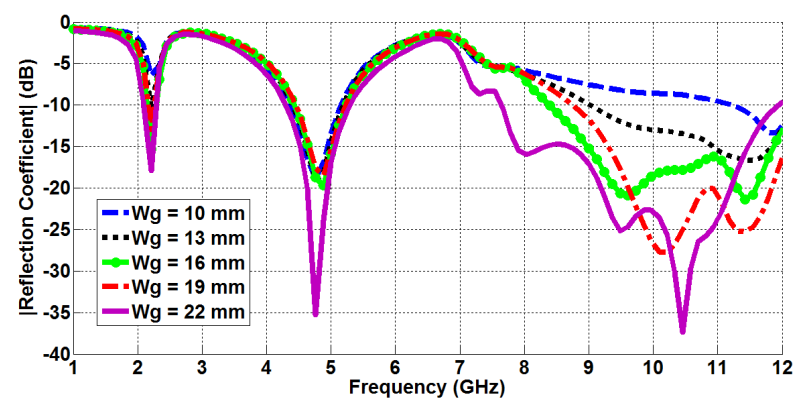

Fig. 7. Effect of partial ground strip width $W_{\mathrm{g}}$ variation on |Reflection Coefficient| (dB).

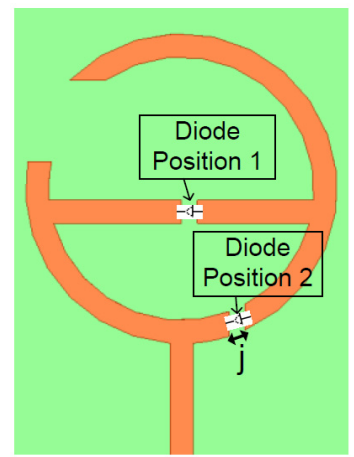

Fig. 8. Identification of diode positions. Dimension ( $\mathrm{mm})$ is $\mathrm{j}=1$.

operated simultaneously. The PIN diodes are hence integrated in the antenna design in such a way that both diodes can be turned 'ON' and 'OFF' simultaneously. After the identification of PIN diodes positions, the PIN diodes were also incorporated in the simulation model using RLC boundary conditions. Incorporation of PIN diodes in the simulation model helped in optimizing the effect of PIN diodes on impedance matching and far-field characteristics of the proposed design. In particular, a small rectangular strip with RLC boundary setup was used to realize PIN diodes in simulation model. For 'OFF' state of the PIN diode, a $1 \mathrm{k} \Omega$ resistance was placed in parallel to a $0.1 \mathrm{pF}$ capacitance, which were then placed in series with an inductance of $0.5 \mathrm{nH}$. Whereas, inductance of $0.5 \mathrm{nH}$ placed in series with $0.8 \Omega$ resistance, was used to realize PIN diodes 'ON' state in the simulation environment [31]. The 'OFF' states of PIN diodes allow the proposed antenna to resonate at dual band by suppressing the $(2.16-2.27) \mathrm{GHz}$ band. Whereas in the 'ON' states PIN diodes provide continuous current path to the radiating patch, allowing the antenna to operate at three frequency bands.

\subsection{Surface Current Plots}

The surface current plots of the proposed design in $\mathrm{PIN}$ diodes 'OFF' and ' $\mathrm{ON}$ ' states are demonstrated in Fig. 9 and Fig. 10, respectively, to accurately observe the resonance behavior. Figure 9 represents the surface current plots for both patch and ground at $3.42 \mathrm{GHz}$ and $8.02 \mathrm{GHz}$. The current plots clearly indicate the respective areas of the antenna design responsible for resonant frequencies in the diodes 'OFF' state. The contribution of the small rectangular strip on the bottom side of the antenna in attainment of $8.02 \mathrm{GHz}$ resonant frequency can also be noticed in Fig. 9.

Figure 10, on the other hand, represents the surface current plots for both patch and ground in the diodes ' $\mathrm{ON}$ ' state. The surface currents in Fig. 10 have been plotted at 2.21, 4.85, 8.02, and 10.19 GHz. Figure 10(A) represents the surface currents at $2.21 \mathrm{GHz}$. It can be observed that both diodes at position 1 and 2 are responsible for this resonant frequency. In addition, the upper and lower half of the circular loop along with the rectangular middle strip is also responsible for achieving the $2.21 \mathrm{GHz}$ frequency band. 


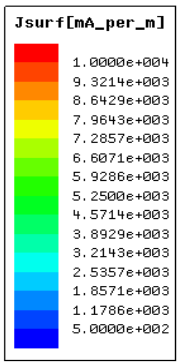

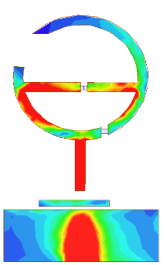

(A)

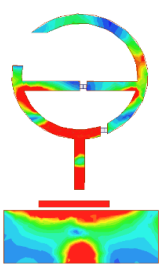

(B)
Fig. 9. Surface current plots (for patch and ground) of the proposed antenna design in the PIN diodes ' $O F F$ ' state: (A) at $3.42 \mathrm{GHz}$ and (B) at $8.02 \mathrm{GHz}$.

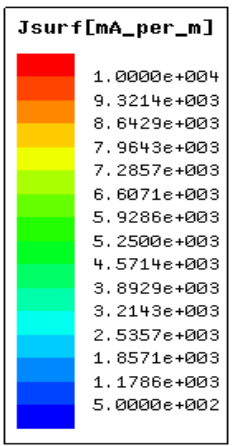

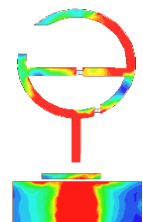

(A)

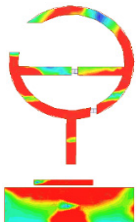

(C)

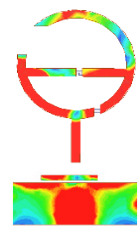

(B)

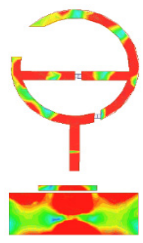

(D)
Fig. 10. Surface current plots (for patch and ground) of the proposed antenna design in the PIN Diodes 'ON' state: (A) at $2.21 \mathrm{GHz},(\mathrm{B})$ at $4.85 \mathrm{GHz},(\mathrm{C})$ at $8.02 \mathrm{GHz}$ and (D) at $10.19 \mathrm{GHz}$.

Figure 10(B) clearly indicates the contribution of diode at position 2 in achieving $4.85 \mathrm{GHz}$ resonant frequency. Primarily, lower half of the circular loop is responsible for $4.85 \mathrm{GHz}$. Figures $10(\mathrm{C})$ and (D) indicate the current plots at $8.02 \mathrm{GHz}$ and $10.19 \mathrm{GHz}$, respectively. It can be clearly observed that wideband operation from $7.54 \mathrm{GHz}$ to $12 \mathrm{GHz}$ can be attributed to the 'ON' state of both PIN diodes, because the complete antenna structure is involved in achieving the $10.19 \mathrm{GHz}$ resonant frequency. The partial ground is involved in generation of all three frequency bands.

\section{Results and Discussion}

To check the efficacy and validation of the proposed structure, the antenna was fabricated on FR4 epoxy substrate having relative permittivity of 4.4, thickness of $1.6 \mathrm{~mm}$, and a loss tangent of 0.02. Skyworks PIN diodes (model pat number: SMP 1322) [32] were used in the fabricated prototype of the antenna. For isolation of RF and DC currents, RF chokes manufactured by minicircuit (part number: ADCH-80A) were used in the fabricated prototype, as indicated in Fig. 11. The RF chokes were selected because of their low DC resistance, low parasitic capacitance, and high impedance over the targeted range of frequencies [33].

\subsection{Reflection Coefficient}

A fully calibrated Agilent N5245B PNA-X Network Analyzer was used for measuring the magnitude of reflection coefficient, in order to observe the impedance matching characteristics of the fabricated prototype and for the proposed design validation. It was observed that good agreement exists between measured and simulated results. Minor disagreement between the results can be attributed to nonideal behavior of PIN diodes and imperfections encountered during antenna fabrication process. However, it is observed that the |Reflection Coefficient $\mid(\mathrm{dB})$ is less than -10 for all resonant frequencies in both diodes ' $O N$ ' and 'OFF' states. Figure 12 represents the simulated |Reflection Coefficient| (dB) results for four different diode configurations. It can be clearly observed that diode 2 controls the $4.85 \mathrm{GHz}$ frequency band. Diode 2 is also responsible for controlling the bandwidth of X-band. In addition, $2.21 \mathrm{GHz}$ and $3.42 \mathrm{GHz}$ bands are being controlled by both diodes 1 and 2 . The simulated and measured |Reflection Coefficient| $(\mathrm{dB})$ results in both PIN diodes 'OFF' and 'ON' states are represented in Fig. 13. It can be observed that $3.42 \mathrm{GHz}$ band in PIN diodes ' $\mathrm{OFF}$ ' state shifts to $4.85 \mathrm{GHz}$ in PIN diodes ' $\mathrm{ON}$ ' state. Table 1 represents the simulated and measured operating frequencies along with bandwidth for both diodes 'OFF' and 'ON' states. As shown in Fig. 13 and Tab. 1, the proposed antenna offers a multi-reconfigurability approach covering both frequency and bandwidth aspects.

\subsection{Far Field Characteristics}

The simulated and measured radiation patterns of the proposed design in PIN diodes 'OFF' and 'ON' states are illustrated in Fig. 14 and Fig. 15, respectively. The radiation patterns were measured in an anechoic chamber facility available in the National University of Sciences and Technology, Islamabad, Pakistan. Figure 14 represents $\mathrm{H}$ plane (xz plane) and $\mathrm{E}$ plane (yz plane) radiation patterns for PIN diodes 'OFF' state at $3.42 \mathrm{GHz}$ and $8.02 \mathrm{GHz}$. Similarly, Figure 15 represents the $\mathrm{H}$ plane (xz plane) and E plane (yz plane) radiation patterns in the PIN diodes 'ON' state at 2.21, 4.85, 8.02, and $10.19 \mathrm{GHz}$. Overall, the simulated and measured results agree with each other. Slight discrepancies observed can be attributed to nonideal behavior of PIN diodes, fabrication, and measurement imperfections. The radiation pattern at $8.02 \mathrm{GHz}$

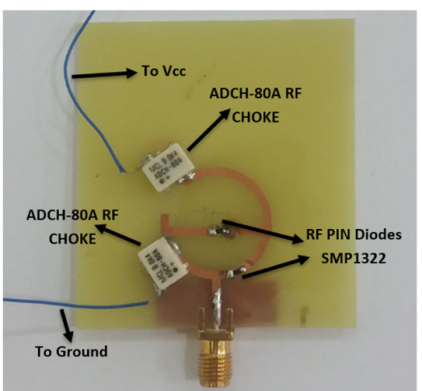

Fig. 11. Fabricated prototype of the proposed design. 


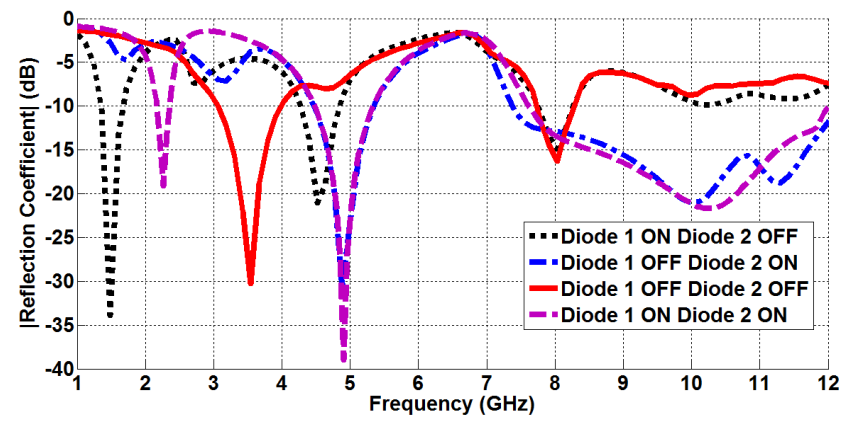

Fig. 12. Simulated |Reflection Coefficient $\mid(\mathrm{dB})$ results of the proposed antenna.

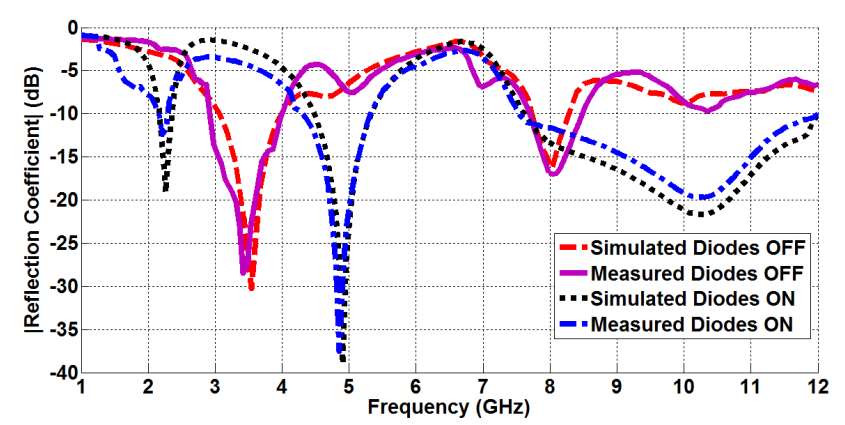

Fig. 13. Simulated and measured |Reflection Coefficient $\mid$ (dB) results of the proposed antenna in diodes ' $\mathrm{ON}$ ' and 'OFF' states.

\begin{tabular}{|c|c|c|}
\hline State & Simulated Results & Measured Results \\
\hline \multirow{2}{*}{$\begin{array}{l}\text { Diodes } \\
\text { 'OFF' }\end{array}$} & $\begin{array}{l}1^{\text {st }} \text { band: } 3.061-4.025 \mathrm{GHz} \text {, } \\
\text { bandwidth: } 0.964 \mathrm{GHz} \\
\text { (center frequency } 3.54 \mathrm{GHz} \\
\text { with } \mid \text { Reflection Coefficient } \mid \\
\text { of }-30.23 \mathrm{~dB} \text { ) }\end{array}$ & $\begin{array}{l}1^{\text {st }} \text { band: } 2.92-3.97 \mathrm{GHz} \text {, } \\
\text { bandwidth: } 1.05 \mathrm{GHz} \\
\text { (center frequency } 3.42 \mathrm{GHz} \\
\text { with } \mid \text { Reflection Coefficient } \\
\text { of }-28.48 \mathrm{~dB} \text { ) }\end{array}$ \\
\hline & $\begin{array}{l}2^{\text {nd }} \text { band: } 7.73-8.36 \mathrm{GHz} \text {, } \\
\text { bandwidth: } 0.63 \mathrm{GHz} \\
\text { (center frequency } 8.03 \mathrm{GHz} \\
\text { with } \mid \text { Reflection Coefficient| } \\
\text { of }-16.31 \mathrm{~dB} \text { ) }\end{array}$ & $\begin{array}{l}2^{\text {nd }} \text { band: } 7.71-8.48 \mathrm{GHz}, \\
\text { bandwidth: } 0.77 \mathrm{GHz} \\
\text { (center frequency } 8.02 \mathrm{GHz} \\
\text { with } \mid \text { Reflection Coefficient } \mid \\
\text { of }-17.03 \mathrm{~dB} \text { ) }\end{array}$ \\
\hline \multirow{3}{*}{$\begin{array}{l}\text { Diodes } \\
\text { 'ON' }\end{array}$} & $\begin{array}{l}1^{\text {st }} \text { band: } 2.155-2.34 \mathrm{GHz}, \\
\text { bandwidth: } 0.185 \mathrm{GHz} \\
\text { (center frequency } 2.265 \mathrm{GHz} \\
\text { with } \mid \text { Reflection Coefficient } \\
\text { of }-19.12 \mathrm{~dB} \text { ) } \\
\end{array}$ & $\begin{array}{l}1^{\text {st }} \text { band: } 2.16-2.27 \mathrm{GHz}, \\
\text { bandwidth: } 0.11 \mathrm{GHz} \\
\text { (center frequency } 2.21 \mathrm{GHz} \\
\text { with } \mid \text { Reflection Coefficient } \mid \\
\text { of }-12.4 \mathrm{~dB} \text { ) } \\
\end{array}$ \\
\hline & $\begin{array}{l}2^{\text {nd }} \text { band: } 4.52-5.29 \mathrm{GHz}, \\
\text { bandwidth: } 0.77 \mathrm{GHz} \\
\text { (center frequency } 4.905 \mathrm{GHz} \\
\text { with } \mid \text { Reflection Coefficient } \mid \\
\text { of }-38.99 \mathrm{~dB} \text { ) }\end{array}$ & $\begin{array}{l}2^{\text {nd }} \text { band: } 4.3-5.3 \mathrm{GHz}, \\
\text { bandwidth: } 1 \mathrm{GHz} \\
\text { (center frequency } 4.85 \mathrm{GHz} \\
\text { with } \mid \text { Reflection Coefficient| } \\
\text { of }-37.5 \mathrm{~dB} \text { ) }\end{array}$ \\
\hline & $\begin{array}{l}3^{\text {rd }} \text { band: } 7.625-12 \mathrm{GHz} \text {, } \\
\text { bandwidth: } 4.375 \mathrm{GHz} \\
\text { (center frequency } 10.35 \mathrm{GHz} \\
\text { with } \mid \text { Reflection Coefficient| } \\
\text { of }-21.63 \mathrm{~dB} \text { ) }\end{array}$ & $\begin{array}{l}3^{\text {rd }} \text { band: } 7.54-12 \mathrm{GHz} \text {, } \\
\text { bandwidth: } 4.46 \mathrm{GHz} \\
\text { (center frequency } 10.19 \mathrm{GHz} \\
\text { with } \mid \text { Reflection Coefficient| } \\
\text { of }-19.7 \mathrm{~dB} \text { ) }\end{array}$ \\
\hline
\end{tabular}

Tab. 1. Comparison of simulated and measured |Reflection Coefficient $(\mathrm{dB})$ results.

remains fairly same in both PIN diodes 'ON' and 'OFF' states but the peak gain changes from $3.37 \mathrm{dBi}$ in the 'OFF' state to $3.26 \mathrm{dBi}$ in the 'ON' state which can be attributed to incorporation of active device, that is, PIN diodes. Table 2 presents the simulated and measured values for peak gain and radiation efficiency, in both diodes 'ON' and 'OFF' states, respectively. All peak gains have been computed in the E plane. To highlight the advantages of the presented antenna, a summarized comparison of this work with related literature is presented in Tab. 3. It can be observed from Tab. 3 that only the proposed work targets $\mathrm{X}$-band along with $4 \mathrm{G}$ and $5 \mathrm{G}$ operating frequencies as compared to other available antenna structures in literature.

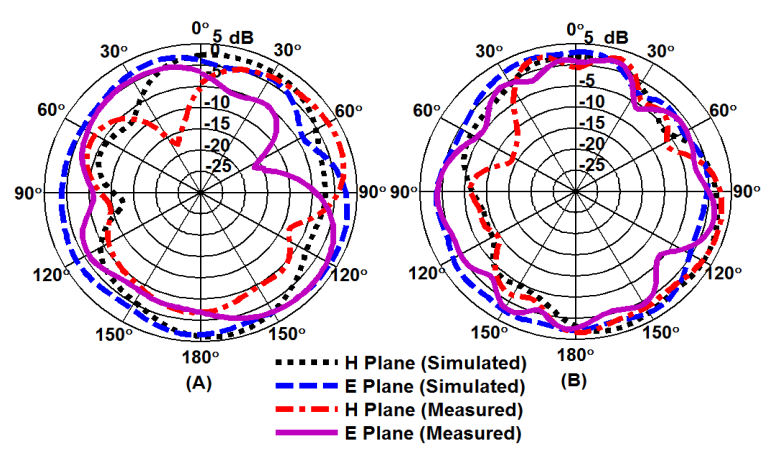

Fig. 14. Simulated and measured radiation patterns of the proposed antenna design in the PIN diodes 'OFF' state: (A) at $3.42 \mathrm{GHz}$ and (B) at $8.02 \mathrm{GHz}$.

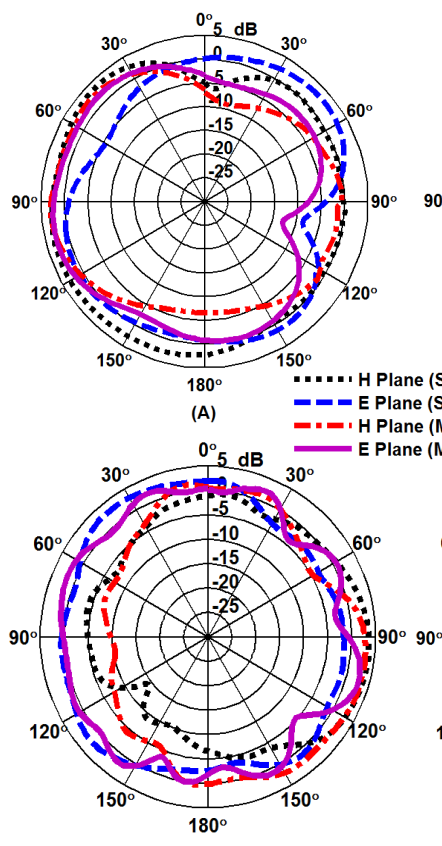

(C)

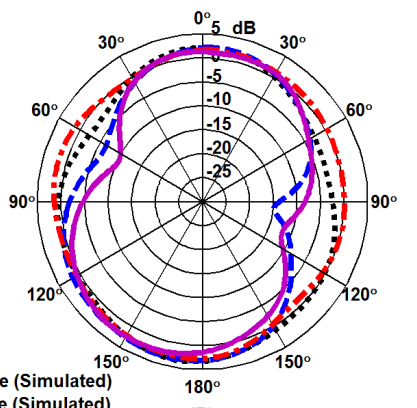

(B) $0^{0} \mathrm{~d} \mathrm{~dB} \quad 30^{\circ}$

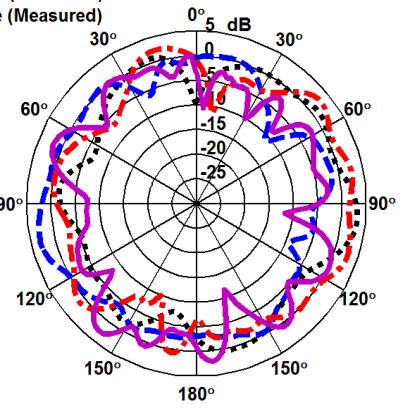

(D)
Fig. 15. Simulated and measured radiation patterns of the proposed antenna design in the PIN diodes ' $\mathrm{ON}$ ' state: (A) at $2.21 \mathrm{GHz},(\mathrm{B})$ at $4.85 \mathrm{GHz},(\mathrm{C})$ at $8.02 \mathrm{GHz}$ and (D) at $10.19 \mathrm{GHz}$.

\begin{tabular}{|c|c|c|c|c|c|}
\hline \multirow{2}{*}{$\begin{array}{c}\text { Diodes } \\
\text { State }\end{array}$} & \multirow{2}{*}{$\begin{array}{c}\text { Freq } \\
\mathbf{( G H z )}\end{array}$} & $\begin{array}{c}\text { Seak } \\
\text { Gain } \\
(\mathbf{d B i})\end{array}$ & $\begin{array}{c}\text { Radiation } \\
\text { Efficiency } \\
(\mathbf{\%})\end{array}$ & $\begin{array}{c}\text { Peak } \\
\text { Gain } \\
(\mathbf{d B i})\end{array}$ & $\begin{array}{c}\text { Radiation } \\
\text { Efficiency } \\
(\%)\end{array}$ \\
\hline OFF & 3.42 & 4.09 & 88.03 & 3.03 & 82.48 \\
\hline OFF & 8.02 & 3.82 & 86.67 & 3.37 & 81.31 \\
\hline ON & 2.21 & 3.53 & 89.42 & 3.06 & 83.27 \\
\hline ON & 4.85 & 3.49 & 85.56 & 2.81 & 78.64 \\
\hline ON & 8.02 & 3.78 & 85.14 & 3.26 & 77.39 \\
\hline ON & 10.19 & 3.32 & 84.26 & 2.92 & 78.48 \\
\hline
\end{tabular}

Tab. 2. Peak gain and radiation efficiency results for the proposed antenna. 


\begin{tabular}{|c|c|c|c|c|c|}
\hline Ref & $\begin{array}{c}\text { Antenna } \\
\text { Shape/ } \\
\text { Targeted } \\
\text { Parameter }\end{array}$ & $\begin{array}{c}\text { Antenna } \\
\text { Size }\left(\mathrm{mm}^{2}\right) / \\
\text { Switching } \\
\text { Elements }\end{array}$ & $\begin{array}{c}\text { Operating } \\
\text { Frequency } \\
\text { Bands }\end{array}$ & $\begin{array}{c}\text { Biasing } \\
\text { Network }\end{array}$ & $\begin{array}{l}\text { Peak } \\
\text { Gain }\end{array}$ \\
\hline [7] & $\begin{array}{c}\text { Octagon/ } \\
\text { Polarization }\end{array}$ & $\begin{array}{c}50.8 \times 50.8 / \\
4 \text { MEMS } \\
\text { Switches }\end{array}$ & $3.8 \mathrm{GHz}$ & $\begin{array}{c}\text { Microstrip } \\
\text { lines and } \\
\text { radial } \\
\text { stubs }\end{array}$ & $4.9 \mathrm{dBi}$ \\
\hline [8] & $\begin{array}{c}\text { Dual Side } \\
\text { Vivaldi/ } \\
\text { Frequency }\end{array}$ & $\begin{array}{c}30 \times 30 / \\
\text { Varactor } \\
\text { Diode }\end{array}$ & $\begin{array}{c}6.16-6.6 \\
\mathrm{GHz}\end{array}$ & $\begin{array}{c}\text { External } \\
\text { Biasing } \\
\text { Tee } \\
\end{array}$ & $\begin{array}{l}6.77 \\
\mathrm{dBi}\end{array}$ \\
\hline [9] & $\begin{array}{c}\text { Annular Slot/ } \\
\text { Frequency, } \\
\text { Radiation } \\
\text { Pattern }\end{array}$ & $\begin{array}{c}50 \times 50 / 4 \\
\text { PIN Diodes }\end{array}$ & $\begin{array}{c}5.2,5.8 \& \\
6.4 \mathrm{GHz}\end{array}$ & $\begin{array}{l}\text { Microstrip } \\
\text { radial } \\
\text { stubs }\end{array}$ & - \\
\hline [10] & $\begin{array}{l}\text { Square Ring/ } \\
\text { Frequency, } \\
\text { Polarization }\end{array}$ & $\begin{array}{c}60 \times 65 / 2 \\
\text { PIN Diodes }\end{array}$ & $\begin{array}{l}2.4,3.4 \& \\
4.18 \mathrm{GHz}\end{array}$ & $\begin{array}{c}\text { RF } \\
\text { Chokes }\end{array}$ & $\begin{array}{c}4.01 \\
3.65 \& \\
3.07 \\
\mathrm{dBi} \\
\end{array}$ \\
\hline [11] & $\begin{array}{c}\text { Planar } \\
\text { Inverted F/ } \\
\text { Frequency }\end{array}$ & $\begin{array}{l}42.5 \times 80 / 3 \\
\text { PIN Diodes }\end{array}$ & $\begin{array}{c}1.8,2.1, \\
2.4,3.5,3.7 \\
\& 5.8 \mathrm{GHz}\end{array}$ & $\begin{array}{c}\text { RLC } \\
\text { Circuit }\end{array}$ & $\begin{array}{c}3.34, \\
2.8, \\
5.16, \\
3.95, \\
5.05 \& \\
6.98 \\
\mathrm{dBi} \\
\end{array}$ \\
\hline [13] & $\begin{array}{c}\text { Slotted } \\
\text { Rectangle/ } \\
\text { Bandwidth }\end{array}$ & $\begin{array}{c}25 \times 50 / 2 \\
\text { PIN Diodes }\end{array}$ & $\begin{array}{c}2.4-5.5 \\
\mathrm{GHz}\end{array}$ & $\begin{array}{c}\text { RLC } \\
\text { Circuit }\end{array}$ & - \\
\hline [15] & $\begin{array}{l}\text { Ring Slot } \\
\text { Inspired/ } \\
\text { Frequency, } \\
\text { Bandwidth }\end{array}$ & $\begin{array}{c}60 \times 80 / 2 \\
\text { PIN Diodes } \\
\& 2 \\
\text { Varactor } \\
\text { Diodes }\end{array}$ & $\begin{array}{c}1.35-6.2 \\
\mathrm{GHz}, 2.55- \\
3.2 \mathrm{GHz}\end{array}$ & $\begin{array}{c}\text { RF } \\
\text { Chokes }\end{array}$ & $\begin{array}{l}5.12 \\
\mathrm{dBi}\end{array}$ \\
\hline $\begin{array}{l}\text { This } \\
\text { Work }\end{array}$ & $\begin{array}{l}\text { Circular } \\
\text { Loop } \\
\text { Inspired/ } \\
\text { Frequency, } \\
\text { Bandwidth }\end{array}$ & $\begin{array}{c}50 \times 55 / 2 \\
\text { PIN Diodes }\end{array}$ & $\begin{array}{l}2.21,3.42 \\
4.85,8.02 \\
10.19 \mathrm{GHz}\end{array}$ & $\begin{array}{c}\text { RF } \\
\text { Chokes }\end{array}$ & $\begin{array}{c}3.53, \\
4.09 \\
3.49 \\
3.82 \& \\
3.32 \\
\mathrm{dBi}\end{array}$ \\
\hline
\end{tabular}

Tab. 3. Comparison with related literature.

\section{Conclusion}

This paper presents concepts of frequency and bandwidth reconfigurability, using a circular loop inspired structure with PIN diodes integration. It is concluded that PIN diodes can be effectively used to control the switching of different frequency bands as well as the operating bandwidth of a printed antenna structure. Switching between different frequency bands can be adopted as per the required application. The notion of frequency switching is represented by first operating the antenna in triband configuration (at 2.21, 4.85, and $10.19 \mathrm{GHz}$ ) in the PIN diodes 'ON' state and then by operating the antenna in dual band configuration, by suppressing the $2.21 \mathrm{GHz}$ band and shifting the $4.85 \mathrm{GHz}$ band to $3.42 \mathrm{GHz}$, in the PIN diodes 'OFF' state. Furthermore, the notion of bandwidth switching is demonstrated by first operating the antenna at a wideband covering $7.54 \mathrm{GHz}-12 \mathrm{GHz}$ in the PIN diodes 'ON' state followed by operating the antenna in a narrowband covering $7.71 \mathrm{GHz}-8.48 \mathrm{GHz}$ in the PIN diodes 'OFF' state. The proposed design was fabricated, and results were measured to validate the simulated results. It can be concluded that the proposed antenna design owing to its operating frequencies is suitable to be used in modern $4 \mathrm{G}$, $5 \mathrm{G}$, and $\mathrm{X}$-band communications.

\section{Acknowledgments}

The authors would like to acknowledge the National Institute of Electronics, Islamabad for fabrication of the prototype. In addition, authors would also like to thank the Department of Electrical and Computer Engineering, COMSATS University Islamabad, and the Research Institute for Microwave and Millimeter-wave Studies, NUST, Islamabad for measurement and testing services.

\section{References}

[1] EL NABAOUI, D., TAJMOUATI, A., ZBITOU, J., et al. Multiband fractal CPW antenna for GPS, WiMAX and IMT applications. In 2017 International Conference on Wireless Technologies, Embedded and Intelligent Systems (WITS). Fez (Morocco), 2017, p. 1-5. DOI: 10.1109/WITS.2017.7934596

[2] NGUYEN, V., PARK, B., PARK, S., et al. A planar dipole for multiband antenna systems with self-balanced impedance. IEEE Antennas and Wireless Propagation Letters, 2014, vol. 13, p. 1632-1635. DOI: 10.1109/LAWP.2014.2347952

[3] ARIS, M. A., ALI, M. T., ABD RAHMAN, N. H., et al. Frequency reconfigurable aperture-coupled microstrip patch antenna using defected ground structure. In 2015 IEEE International $R F$ and Microwave Conference (RFM). Kuching (Malaysia), 2015, p. 200-204. DOI: 10.1109/RFM.2015.7587744

[4] JHAMB, K., LI, L., RAMBABU, K. Frequency adjustable microstrip annular ring patch antenna with multi-band characteristics. IET Microwaves, Antennas \& Propagation, 2011, vol. 5, no. 12, p. 1471-1478. DOI: 10.1049/iet-map.2010.0571

[5] BALANIS, C. A. Antenna Theory Analysis and Design. 4th ed. New York (USA): John Wiley \& Sons, 2016. ISBN 978-1-11864206-1

[6] BERNHARD, J. T. Reconfigurable Antennas. San Rafael, (California, USA): Morgan and Claypool Publishers, 2007. DOI: 10.2200/S00067ED1V01Y200707ANT004

[7] GRAU, A., ROMEU, J., LEE, M. J., et al. A dual-linearlypolarized MEMS-reconfigurable antenna for narrowband MIMO communication systems. IEEE Transactions on Antennas and Propagation, 2010, vol. 58, no. 1, p. 4-17. DOI:10.1109/tap.2009.2036197

[8] TAWK, Y., COSTAntine, J., Christodoulou, C. G. A varactor based reconfigurable filtenna. IEEE Antennas and Wireless Propagation Letters, 2012, vol. 11, p. 716-719. DOI: 10.1109/LAWP.2012.2204850

[9] NIKOLAOU, S. BAIRAVASUBRAMANIAN, R., LUGO, C., et al. Pattern and frequency reconfigurable annular slot antenna using PIN diodes. IEEE Transactions on Antennas and Propagation, 2006, vol. 54, no. 2, p. 439-448. DOI: 10.1109/TAP.2005.863398

[10] NITURE, D. V., GOVIND, P. A., MAHAJAN, S. P. Frequency and polarization reconfigurable square ring antenna for wireless application. In 2016 IEEE Region 10 Conference (TENCON). Singapore, $2016, \quad$ p. $1302-1306 . \quad$ DOI: 10.1109/TENCON.2016.7848223 
[11] MINH, P. T., THAO, T. T., DUC, N. T, et al. A novel multiband frequency reconfigurable PIFA antenna. In 2016 International Conference on Advanced Technologies for Communications (ATC). Hanoi (Vietnam), 2016, p. 7-12. DOI: 10.1109/ATC.2016.7764832

[12] KIM, Y., YOON, Y. J. A high gain pattern reconfigurable antenna with simple structure. In 2016 IEEE International Symposium on Antennas and Propagation (APSURSI). Fajardo (Puerto Rico), 2016, p. 653-654. DOI: 10.1109/APS.2016.7696035

[13] CHEN, S., CHU, Q., SHINOHARA, N. A bandwidth reconfigurable planar antenna for WLAN/WiMAX applications. In Proceedings of the Asia-Pacific Microwave Conference (APMC). New Delhi (India), 2016, p. 5-9. DOI: 10.1109/apmc.2016.7931467

[14] HUSSAIN, R., SHARAWI, M. S. A cognitive radio reconfigurable MIMO and sensing antenna system. IEEE Antennas and Wireless Propagation Letters, 2015, vol. 14, p. 257-260. DOI: 10.1109/LAWP.2014.2361450

[15] NACHOUANE, H., NAJID, A., TRIBAK, A., et al Reconfigurable and tunable filtenna for cognitive LTE femtocell base stations. International Journal of Microwave Science and Technology, 2016, p. 1-10. DOI: 10.1155/2016/9460823

[16] UNIVERSITY OF NOTRE DAME. $4 G$ Wireless Standard. [Online] Cited 2020-March-10. Available at: https://www3.nd.edu/ mhaenggi/NET/wireless/4G/

[17] QUALCOMM. What Can We Do with $5 G$ NR Spectrum Sharing that Isn't Possible Today? [Online] Cited 2020-March-10. Available at: https://www.qualcomm.com/media/documents/files/new$3 \mathrm{gpp}$-effort-on-nr-in-unlicensed-spectrum-expands-5g-to-newareas.pdf

[18] BHATTACHARYYA, B., BHATTACHARYYA, S. Emerging field in 4G technology, its applications \& beyond-an overview. International Journal of Information and Computation Technology, 2013, vol. 3, no. 4, p. 251-260. ISSN: 0974-2239

[19] ChAMBERS, J. Commercial X-Band: The Technical + Operational Advantages. [Online] Cited 2020-March-11. Available at: http://www.milsatmagazine.com/story.php?number $=1530000863$

[20] PIAO, H., JIN, Y., TAK, J., et al. Compact quad-band slot antenna for GPS L1, WiMAX, and WLAN applications. In 2016 International Symposium on Antennas and Propagation (ISAP). Okinawa (Japan), 2016, p. 808-809. ISBN: 978-4-88552-313-7

[21] Allabouche, K., BOBRovs, V., FERERRO, F., et al. Multiband rectangular dielectric resonator antenna for $5 \mathrm{G}$ applications. In 2017 International Conference on Wireless Technologies, Embedded and Intelligent Systems (WITS). Fez (Morocco), 2017, p. 1-4. DOI: 10.1109/WITS.2017.7934637

[22] FEDERAL COMMUNICATIONS COMMISSION. Advanced Wireless Services (AWS). 32 pages. [Online] Cited 2020-March11. Available at: https://www.fcc.gov/wireless/bureaudivisions/broadband-division/advanced-wireless-services-aws

[23] ASIA-PACIFIC TELECOMMUNITY. APT Report on Frequency Usage of the Band 3400-3600 MHz. [Online] Cited 2020-March11. Available at: https://www.apt.int/sites/default/files/Uploadfiles/AWG/APT-AWG-REP-37-APT_Report_on_34003600MHz.docx

[24] NIVIUK. NR Frequency Band. [Online] Cited 2020-March-11. Available at: http://niviuk.free.fr/nr_band.php

[25] MEHDIPOUR, A., SEBAK, A., TRUEMAN, C. W., et al. Compact multiband planar antenna for $2.4 / 3.5 / 5.2 / 5.8-\mathrm{GHz}$ wireless applications. IEEE Antennas and Wireless Propagation Letters, 2012, vol. 11, p. 144-147. DOI: 10.1109/LAWP.2012.2185915

[26] GAO, X., ZHONG, H., ZHANG, Z., et al. Low-profile planar tripolarization antenna for WLAN communications. IEEE
Antennas and Wireless Propagation Letters, 2010, vol. 9, p. 83-86. DOI: 10.1109/LAWP.2010.2043495

[27] LI, R., FUSCO, V. F., NAKANO, H. Circularly polarized openloop antenna. IEEE Transactions on Antennas and Propagation, 2003, vol. 51, no. 9, p. 2475-2477. DOI: 10.1109/TAP.2003.809845

[28] LI, R., PAN, B., LASKAR, J., et al. A novel low-profile broadband dual-frequency planar antenna for wireless handsets. IEEE Transactions on Antennas and Propagation, 2008, vol. 56, no. 4, p. 1155-1162. DOI: 10.1109/TAP.2008.919171

[29] LIU, W. C., WU, C. M., DAI, Y. Design of triple-frequency microstrip- fed monopole antenna using defected ground structure. IEEE Transactions on Antennas and Propagation, 2011, vol. 59, no. 7, p. 2457-2463. DOI: 10.1109/TAP.2011.2152315

[30] KHAN, M. S., CAPOBIANCO, A. D., IFTIKHAR, A., et al A frequency-reconfigurable series-fed microstrip patch array with interconnecting CRLH transmission lines. IEEE Antennas and Wireless Propagation Letters, 2015, vol. 15, p. 242-245. DOI: 10.1109/LAWP.2015.2439637

[31] SKYWORKS. SMP 1322 Series. [Online] Cited 2019-July-03. Available at: https://www.skyworksinc.com/en/Products/ Diodes/SMP1322-Series

[32] MINI CIRCUITS. ADCH-80A RF Chokel Surf Mount RoHS5. [Online] Cited 2019-July-03. Available at: https://www.minicircuits.com/WebStore/dashboard.html?model=A DCH-80A

\section{About the Authors ...}

Maryam RASOOL received her BS and MS Electrical Engineering degrees from COMSATS University, Islamabad, Pakistan in 2012 and 2015 respectively with distinction. She is currently enrolled in Ph.D. Electrical Engineering at Military College of Signals, (NUST), Islamabad, Pakistan.

Aabia KHAN completed her MS Electrical Engineering from MCS (NUST), Islamabad, Pakistan in 2019. She is a competent professional with interest in the field of antenna.

Farooq BHATTI did his Ph.D. in Radio Physics (RF Electronics) specializing in Microwave and Millimeterwave sources from Shanghai University China in 1992. Presently he is an Associate Professor at MCS NUST.

Bilal IJAZ received the MS degree in Modern Digital Communication Systems from the University of Sussex, U.K., in 2008 and Ph.D. degree in Electrical and Computer Engineering from North Dakota State University, USA, in 2014. Currently he is an Assistant Professor at COMSATS University Islamabad.

Adnan IFTIKHAR received his MS degree in Personal Mobile and Satellite Communication from University of Bradford, England, and Ph.D. degree in Electrical and Computer Engineering from North Dakota State University, USA in 2010 and 2016, respectively. Currently he is an Assistant Professor at COMSATS University Islamabad. 